\title{
Geoinformatika in aplikativna geografija v Sloveniji
}

\author{
Marko Krevs \\ Dr., Oddelek za geografijo, Filozofska fakulteta, Univerza v Ljubljani, \\ Aškerčeva 2, 1000 Ljubljana, Slovenija \\ e-mail: marko.krevs@ff.uni-lj.si
}

\section{Izvleček}

Uporaba geoinformatike v slovenski aplikativni geografiji narašča. Vendar so geoinformacijske možnosti razmeroma skromno izkoriščene. Ocenjeni so glavni vzroki za takšno stanje ter predlagane nekatere spremembe na pedagoškem, znanstveno-raziskovalnem in aplikativno geografskem področju, ki bi pripomogle k uspešnejši rabi geoinformatike $v$ aplikativni geografiji.

Ključne besede: geoinformatika, aplikativna geografija, Slovenija

\section{Geoinformatics and applied geography in Slovenia}

\begin{abstract}
Use of geoinformatics in Slovenian applied geography is growing. But many geoinformatic opportunities remain poorly used. The main reasons for the present conditions are pointed out, and some changes in pedagogic, scientific and appliedgeographic field are suggested to improve the use of geoinformatics in Slovenian applied geography.
\end{abstract}

Key words: geoinformatics, applied geography, Slovenia 


\section{UVOD}

Geoinformatika, ki jo opredeljujemo kot znanost in tehnologijo pridobivanja, hranjenja, posredovanja, analize in predstavljanja geografskih informacij, je na splošno "pisana na kožo« znanstveno-raziskovalni, pedagoški in aplikativni geografiji. V slovenski geografski literaturi, od študentskih seminarskih nalog do doktorskih disertacij, znanstvenih in strokovnih člankov, raziskovalnih poročil, z veseljem ugotavljamo vse pogostejšo uporabo geoinformacijskih orodij. Vendarle se ne moremo znebiti vtisa o razmeroma skromni izkoriščenosti možnosti, ki jih geoinformatika ponuja geografom.

Med glavnimi razlogi za uporabo geoinformatike v posameznih primerih je praviloma vsaj kateri izmed naslednjih (ali kar vsi): objektivn(ejš)a, kompleksnejša obravnava velikih količin podatkov, prepričljiva (bolj razumljiva) predstavitev raziskovalnih spoznanj, časovno-stroškovne koristi, standardiziranost zapisa/organizacije in povezljivost rezultatov raziskave $\mathrm{z}$ drugimi podatki, možnost razvoja novih geografskih metod, možnost uporabe novih informacijskih tehnologij (glede na potrebe uporabnika),... Navedeno kaže na velik potencialni prispevek intenzivnejše in bolj kakovostne rabe geoinformatike v posameznih projektih k njihovi večji uporabni vrednosti (konkurenčnosti), seveda pa tudi k razvoju stroke.

V članku soočimo nekatere značilne geoinformacijske možnosti s prevldujočo rabo geoinformatike v slovenski geografiji. Razmišljamo o možnih vzrokih za ugotovljeno stanje, predvsem pa o poteh do ustreznejšega, učinkovitejšega razvoja in rabe geoinformatike v slovenski (aplikativni) geografiji.

$\mathrm{Na}$ tem mestu se ne sprašujemo, kateri deli aplikativne geografije bolj in kateri manj potrebuje geoinformacijsko podporo. Predpostavljamo, da jo potrebuje in tudi uporablja pretežni del aplikativne geografije. Obenem se pretvarjamo, da je pojmovanje obeh osrednjih pojmov v besedilu, aplikativne geografije in geoinformatike, dovolj enotno, da ju ne poskušamo točneje opredeliti. Še več, menimo, da razločna razmejitev aplikativne od »ostale« (»neaplikativne«?) geografije za našo razpravo ni bistvena, saj je razvoj geoinformatike in aplikativne geografije odvisen od ustreznega delovanja vseh področij »izvajanja« geografije - od izobraževanja, do znanstvenega in strokovnega raziskovanja ter vključevanja geografije v različne sfere družbenega življenja. 


\section{GEOINFORMACIJSKE POTREBE APLIKATIVNE GEOGRAFIJE}

Temeljna "področja uporabe « geoinformatike v aplikativni geografiji lahko razberemo iz opredelitve, navedene v uvodu. Katere konkretnejše oblike rabe geoinformatike prevladujejo v slovenski geografiji? Intervjuji (Krevs 2001), ki smo jih opravili na takratnih petih slovenskih "geografskih ustanovah ${ }^{1}$ so pokazali, da med njimi obstajajo precejšne razlike s tega vidika. Oglejmo si nekatere ugotovitve.

$\mathrm{Na}$ splošno količinsko prevladujejo urejanje podatkov ter kartografski prikazi, analize pa predstavljajo le majhen delež celotne rabe geoinformatike. Temeljna delitev na raziskovalne (inštitute) in pedagoško-raziskovalne ustanove (oddelka za geografijo) se odraža tudi v različni rabi in problematiki uporabe geoinformatike.

$\mathrm{Na}$ inštitutih prevladuje raziskovalno delo, ki je v celoti (na Geografskem inštitutu Antona Melika in Inštitutu za raziskovanje krasa ZRC SAZU) ali vsaj v večji meri (Inštitut za geografijo) geoinformacijsko podprto. Navedenemu ustreza tudi stopnja vpliva geoinformatike na snovanje in organizacijo dela, ki je najvišja na Geografskem inštitutu Antona Melika. Poleg prevladujočega urejanja podatkov, tematske kartografije in statističnih analiz na Inštitutu za raziskovanje krasa in Geografskem inštitutu Antona Melika izvajajo (ali načrtujejo) tudi monitoring določenih procesov $\mathrm{v}$ pokrajini, na primer sledenje podzemskim vodam na krasu ali spreminjanje Triglavskega ledenika. Na obeh ustanovah se v manjši meri ukvarjajo (ali se nameravajo ukvarjati) tudi z modeliranjem oziroma s simulacijami, na primer $\mathrm{z}$ modeliranjem nastajanja kraških jam, simulacijami podzemnega prenašanja polutantov, spreminjanja Triglavskega ledenika. Na Inštitutu za geografijo so imeli dve »geoinformacijski« delvni mesti, medtem ko je bilo poznavanje tovrstnih znanj med večino ostalih

\footnotetext{
${ }^{1}$ Jeseni 2001 smo izvedli intervjuje z izbranimi posamezniki z vseh petih slovenskih "geografskih ustanov«: Inštituta za geografijo (Iztok Sajko), Geografskega inštituta Antona Melika ZRC $S A Z U$ (dr. Matej Gabrovec), Inštituta za raziskovanje krasa ZRC SAZU (dr. Andrej Mihevc), Oddelka za geografijo Pedagoške fakultete v Mariboru (dr. Igor Žiberna) ter Oddelka za geografijo Filozofske fakultete v Ljubljani (avtor tega prispevka). Izbor intervjuvanih je temeljil na njihovi dejavni vlogi pri uveljavljanju in uporabi geoinformatike $v$ svojih ustanovah oziroma $v$ slovenski geografiji; nekateri med njimi so za to delovno področje tudi formalno zadolženi. Zato njihove odgovore uporabimo kot »ekspertne ocene" stanja geoinformatike na posameznih ustanovah in $v$ slovenski geografiji in ne le kot njihova osebna mnenja. Na tem mestu ne ocenjujemo možnih učinkov letošnje ukinitve Inštituta za geografijo ter posledičnih sprememb na Geografskem inštitutu Antona Melika in Oddelku za geografijo v Ljubljani na uporabo geoinformatike $v$ slovenski aplikativni geografiji.
} 
raziskovalcev šibko. Podobne razmere so na Inštitutu za raziskovanje krasa, kjer se poleg dveh "geoinformatikov« s tovrstnimi tematikami občasno ukvarjajo še trije raziskovalci. Na Geografskem inštitutu Antona Melika vsi raziskovalci obvladajo uporabo geoinformatike, vsaj za lastne raziskovalne potrebe. Del tovrstnih nalog si med seboj tudi delijo, na primer kartografijo, geografske informacijske sisteme, digitalizacijo, skrb za posamezne zbirke podatkov.

Med največjimi težavami pri uporabi geoinformatike znotraj svoje ustanove vsi anketirani navajajo težave, ki izvirajo iz uporabe podatkov zelo različne kakovosti (na primer $\mathrm{v}$ različnih merilih oziroma prostorski ločljivosti), pomanjkanje (ali odsotnost) geoinformacijskih delovnih mest z ustrezno izobraženimi oziroma usposobljenimi strokovnjaki, tudi pomanjkanje možnosti (časa, sredstev) vsaj za lastno geoinformacijsko izobraževanje posameznih raziskovalcev. Zanimivo spoznanje je, da Prostorskoinformacijska enota ZRC SAZU ne deluje kot servis za druge inštitute $\mathrm{v}$ okviru skupne organizacije, tako da tudi sodelovanja z Geografskim inštitutom Antona Melika in Inštitutom za raziskovanje krasa praktično ni. Na Inštitutu za geografijo je bilo izpostavljeno pomanjkljivo poznavanje možnosti, ki jih nudi uporaba geoinformatike, med večino, ki je izvajala raziskovalno delo. Na Inštitutu za raziskovanje krasa pogrešajo večjo količino digitalnih naprav za zajem podatkov ter nekatera sicer razširjena geoinformacijska orodja (na primer ArcView, ArcInfo).

Med glavnimi ugodnimi učinki uporabe geoinformatike navajajo olajšano oziroma omogočeno povezovanje $\mathrm{z}$ drugimi strokami in ustanovami.

Večja razlika, kot med inštituti, je med oddelkoma za geografijo v Ljubljani in Mariboru. Na slednjem ni predmeta z geoinformacijskimi vsebinami (nekaj primerov študenti spoznajo le pri geomorfologiji in klimatogeografiji), pred nekaj leti so ukinili tudi predmeta Kvantitativne metode 1 in 2, ki sta pokrivala vsaj del tematike. Ustrezen uvodni geoinformacijski predmet naj bi bil vključen $v$ študijski program $z$ uvedbo nepedagoške smeri študija geografije, s čimer bodo pridobili edino vsaj deloma geoinformacijsko delovno mesto. Doslej je bil le en raziskovalni projekt na oddelku geoinformacijsko podprt. Na ljubljanskem oddelku so v okviru dodiplomskega študija trije predmeti s pretežno geoinformacijskimi vsebinami, na podiplomskem pa še trije (med slednjimi je eden obvezni skupni predmet). V celoti ali vsaj deloma »geoinformacijska« delovna mesta so štiri; poleg nosilca tovrstnih predmetov še dva asistenta ter kartograf-dokumentalist. Pretežni del raziskovalnih projektov, zlasti večjih (ki zajamejo večji del raziskovalcev), je geoinformacijsko podprt. Oba oddelka izpostavljata problem (rednega) financiranja nakupa geoinformacijske opreme, kar je na inštitutih urejeno s posebnim načinom financiranja s strani države. Na ljubljanskem oddelku si študenti (Peršolja 2001) želijo več geoinformacijskih znanj in praktičnega dela, kar še posebej velja za študente 
dvopredmetne pedagoške smeri (zdaj nimajo »pravih « geoinformacijskih študijskih predmetov). Slednje bo morda mogoče deloma uresničiti z ustrezno prilagoditvijo bodočega kreditnega sistema študija. Možnost poglobitve geoinformacijskih znanj za študente samostojne študijske smeri geografije bi omogočala uvedba ustrezne usmeritve študija (v višjih letnikih), ki bi bila povezana tudi z ureditvijo habilitacijskih nazivov nosilcev predmetov in njihovih asistentov ter z ustanovitvijo ustrezne katedre. Že brez omenjenih sprememb študijskega programa in organizacije oddelka pa bi bila izrednega pomena intenzivnejša vključitev geoinformatike (na primer $\mathrm{v}$ obliki primerov, tematik dela seminarskih, diplomskih nalog) v izvajanje že obstoječih »geografskih predmetov«, saj sicer tovrstna znanja in veščine zbledijo že v času dodiplomskega študija.

Zavedamo se, da z intervjuji nismo zajeli vseh, niti ne večine geografov, ki delujejo (tudi) na področju aplikativne geografije. Vsekakor pa smo obravnavali največje »institucionalne zgostitve« slovenskih geografov. Ker je razvoj geoinformatike praviloma $\mathrm{v}$ domeni večjih organizacij, smo prepričani, da so ugotovitve reprezentativne za velik del slovenske geografije.

\section{NEIZKORIŠČENE GEOINFORMACIJSKE MOŽNOSTI}

Izsledki predstavljenih intervjujev ter pregleda obsežne literature potrjujejo prevlado »opisnih« geoinformacijskih metod (od opisnih statističnih metod, tipizacij, do »klasične" tematske kartografije), zajema in urejanja podatkov (tudi že obstoječih) ter različnih metod vrednotenja razmer v pokrajini ali prostorskih politik. Neizkoriščene ali slabo izkoriščene geoinformacijske možnosti pa so na primer dinamično modeliranje (simulacije, metoda scenarijev), razvoj lastnih geoinformacijskih metod (in ne prilagajanje raziskovalnih ciljev razpoložljivim metodam), spletni geoinformacijski izdelki, 3D in dinamična geografska vizualizacija.

Značaj predmeta geografskega proučevanja je na splošno tak, da so navedene neizkoriščene možnosti pomembne že zaradi boljše kakovosti raziskovalnih spoznanj, v aplikativni geografiji pa tudi zaradi prilagajanja "zahtevam trga" (večja prepričljivost, privlačnost, razumljivost, širša dostopnost) in ciljnim skupinam uporabnikov geoinformacij, spodbujanja interdisciplinarnosti, arhiviranja in primerjanja praks.

Glavni vzroki za razmeroma šibko izkoriščenost geoinformacijskih možnosti v slovenski aplikativni geografiji so:

- šibka povezanost med geografskimi in z drugimi ustanovami,

- S sibka povezanost med »znanstveno«, »aplikativno«, »pedagoško« geografijo, 
- zamujene priložnosti za prepletanje geoinformatike in geografije med študijem (pri geografskih predmetih, seminarskih, diplomskih, podiplomskih nalogah),

- omejene izobraževalne možnosti (oprema, podatki, ni usmeritve na dodiplomskem in smeri na podiplomskem študiju, dragi in dolgotrajni geoinformacijski tečaji),

- pomanjkanje ustrezno izobraženih in usposobljenih kadrov ("geoinformatikov"),

- preveč različne oziroma hitro spreminjajoče teme projektov, ki obenem zahtevajo hitre rezultate.

Posebej želimo izpostaviti delno napačno razumevanje geoinformatike kot "orodja za hitro pridobivanje rezultatov". V praksi to velja, če imamo urejene (preverjene) zbirke podatkov, že razvite in preizkušene ustrezne metode, ustrezne geoinformacijsko podkovane sodelavce ter seveda ustrezno opremo. Za velik del »rutinskih« opravil so takšna pričakovanja uresničljiva, zlasti če čas za njihovo geoinformacijsko podprto izvedbo primerjamo s časom, potrebnim za izvedbo »na klasičen način«. Žal pa hitra pot do rezultatov v razmerah prevladujoče vsebinske razdrobljenosti in »kratkoročnosti« geografskega raziskovanja pogosto pomeni ohranjanje številnih pomanjkljivosti tega raziskovanja, za katere smo pričakovali, da bodo z uveljavitvijo geoinformatike odpravljene. »Šolski primer« neučinkovite uporabe geoinformacijskih orodij v slovenski aplikativni geografiji je poskus opredeljevanja volilnih okrajev po naročilu Državnega zbora (glej tudi Krevs 2000). Bistveni vzrok geoinformacijske neučinkovitosti izvedbe projekta je bila zahteva, da so rezultati na mizi pogajalske skupine $\mathrm{v}$ nekaj dneh (kasneje se je rok izvedbe podaljšal na nekaj tednov). V literaturi so dokumentirani številni primeri uspešne uporabe geoinformacijsko podprtih postopkov za opredeljevanje volilnih okrajev, ki omogočajo čimbolj nepristranske in variantne rešitve problema. Njihov razvoj je potekal daljši čas in se nadaljuje. V omenjenem slovenskem primeru pa so bila geoinformacijska orodja uporabljena le kot "prostorski kalkulator « (za seštevanje števila volilcev iz sosednjih območij) ter za kartografski prikaz rezultatov. Poudariti moramo izredno prizadevnost vseh sodelujočih z Inštituta za geografijo, Oddelka za geografijo Filozofske fakultete v Ljubljani, z ustanov, ki so izvajalcem posredovale ustrezne podatke ter ustrezno geoinformacijsko opremljenost sodelujočih ustanov. Večina okoliščin je bila torej z vidika izvedbe projekta ugodna, ni pa bilo dovolj časa za izdelavo ustreznih geoinformacijskih metod in njihovo »vskladitev« $\mathrm{z}$ zahtevami politike. 


\section{PRILOŽNOSTI ZA IZBOLJŠANJE GEOINFORMACIJ- SKE PODPORE APLIKATIVNI GEOGRAFIJI}

Dejanja, ki bi po našem mnenju $\mathrm{v}$ danih razmerah pomembneje vplivala na kakovost uporabe geoinformatike $\mathrm{v}$ slovenski (aplikativni) geografiji, segajo na izobraževalno, raziskovalno in organizacijsko področje. Na prvem bi korak naprej pomenila uvedba že omenjene geoinformacijske usmeritve $\mathrm{v}$ višjih letnikih dodiplomskega študija ter tovrstne smeri na podiplomskem študiju, z nujno navezanostjo na potekajoče raziskovalne projekte. To bi prispevalo $\mathrm{k}$ bolj »inženirskemu « obvladovanju geoinformacijskih orodij ter k samozavestnejšemu nastopanju geografov $»$ v praksi«. Drugo pomembno dejanje bi bila delna vskladitev dela različnih geografskih in sorodnih ustanov, ali vsaj tesnejše delovno povezovanje med njimi. To bi bilo smiselno predvsem za tematike, ki so jim skupne in obenem njihova izvedba ni pod pretiranim časovnim pritiskom. Učinki tovrstnega povezovanja bi bili ugodni z vidika omenjene razdrobljenosti raziskovalnega dela med ustanovami in znotraj njih, z vidika racionalizacije določenih del, skupnega iskanja tržnih niš ali ustvarjanja novih geoinformacijskih potreb. Morda pa bi bilo smiselno obuditi tudi razmišljanja o neki obliki skupnega geoinformacijskega servisa.

\section{SKLEP}

$\mathrm{V}$ dosedanjem besedilu smo razloge za le delno uspešno povezovanje med geoinformatiko in aplikativno geografijo iskali le znotraj geografije. Kaj pa odzivi potencialnih uporabnikov geografskih informacij oziroma storitev? Ti so se, vsaj v Sloveniji, žal navadili na obstoječo geoinformacijsko raven geografskih storitev, sodobnejših, zahtevnejših geoinformacijskih rešitev pa večinoma niti ne povezujejo z geografijo in jih iščejo $\mathrm{v}$ drugih strokah, na primer $\mathrm{v}$ geodeziji, računalništvu, celo strojništvu! Predpostavljamo, da si želimo geografi vsaj nekoliko izboljšati tovrstni »image«. Vendar se moramo zavedati, da obstoječih načinov dela in pogledov uporabnikov geografskih informacij ne bo mogoče spremeniti v kratkem času.

Ob tem razmišljanju se odpirajo tudi širši pogledi na priložnosti, ki jih ponuja geoinformatika kot samostojna multidisciplinarna veda. Zaradi njene temeljne usmerjenosti »v prakso« je nujna tesna prepletenost znanstvenega in strokovnega dela, uporabe in razvoja tehnologije (vključno z določenimi deli proizvodnje), ter različnih področij praktične uporabe geoinformacij. Prevla- 
dujoči izobraževalni sistemi v »razvitih« državah z bolj ali manj togimi delitvami po posameznih strokah ${ }^{2}$ praviloma ne ponuja pravih možnosti za razvoj geoinformatike, saj posamezne stroke preveč utesnjujejo njen razvoj, povezanost $\mathrm{z}$ industrijo in »prakso « pa je pogosto prešibka. Problem na izobraževalnem področju (posredno, s časovnim zamikom pa tudi v aplikativni geografiji) $\mathrm{v}$ Evropi in $\mathrm{v}$ drugi gospodarsko razvitih delih sveta $\mathrm{z}$ večjim ali manjšim uspehom na primer rešujejo na naslednje načine:

- $\quad \mathrm{s}$ širjenjem količine geoinformacijskih vsebin in prakse na dodiplomskem študiju različnih strok, ne le geografije,

- $\quad$ z uvajanjem specializacij iz geoinformatike (ali njenega dela) po končanem dodiplomskem študiju,

- $\quad \mathrm{z}$ uvajanjem multidisciplinarnih dodiplomskih in podiplomskih študijskih programov iz geoinformatike ${ }^{3}$.

Povezava navedenih izobraževalnih programov $\mathrm{z}$ industrijo in konkretnimi končnimi uporabniki je marsikje nujna, saj sta lahko to edina načina zagotavljanja virov financiranja relativno velikih stroškov vzpostavljanja in vzdrževanja geoinformacijskih orodij in zbirk podatkov.

Za konec pa še drobno razmišljanje o »izganjanju strahov«. Geograf je v preteklosti za doseganje svojih pedagoških in raziskovalnih ciljev pogumno, ustvarjalno uporabljal, po potrebi pa tudi predelal številna orodja, naprave in metode, ki so izvirale z drugih strokovnih področij, od meteoroloških merilnih naprav, postopkov in naprav za analizo prsti, do anketiranja in statističnih metod. V zadnjem desetletju, ki sovpada $\mathrm{z}$ obdobjem izvajanja pouka $\mathrm{z}$ geoinformacijskimi vsebinami na dodiplomskem študiju na Oddelku za geografijo Filozofske fakultete v Ljubljani, opažamo zmerno navdušenje nad uporabo obstoječih, v geoinformacijska orodja že vgrajenih postopkov, zlasti za nekatere analize podatkov in kartografske prikaze. Ne znamo pa pojasniti strahu študentov (ti pa ta strah ohranijo tudi po diplomi) pred ustvarjalno uporabo ali predelavo ${ }^{4}$ teh postopkov $-\mathrm{s}$ čimer bi izkoristili tudi geoinformacijske možnosti, ki smo jih $\mathrm{v}$ tem besedilu navedli med slabo izkoriščenimi ali neizkoriščenimi. Tovrstne »nadgradnje« bi, v ekonomskem jeziku, pomenile tudi del »dodane vrednosti«, ki bi jo posameznik in stroka prispevala $\mathrm{k}$ razvoju, ugledu, uporabnosti geoinformatike na eni in (aplikativne) geografije na drugi strani.

\footnotetext{
${ }^{2}$ Te delitve pa se ohranjajo v bolj ali manj »ostri« obliki tudi izven procesa izobraževanja.

${ }^{3}$ Nazoren je nemški primer Fakultete za geografijo in informatiko.

${ }^{4}$ Predelava geoinformacijskih orodij praviloma vključuje tudi preprosto „,programiranje“, ki je največkrat komaj kaj bolj zapleteno od nizanja posameznih ukazov, ki jih uporabniki sicer izvajajo s pomočjo menijev $v$ določenem geoinformacijskem programu.
} 
Zato bo potrebno več storiti za odpravljanje tovrstnih strahov - ne le zaradi razvoja slovenske geoinformatike, temveč tudi zaradi razvoja slovenske (aplikativne) geografije.

\section{Literatura in viri:}

Frank, A., Fedra, K., 1999. Train the trainers. Gradivo za udeležence. Izobrževalno središče za geomatiko. Projekt ONIX: Inštitut za geodezijo in fotogrametrijo, Ministrstvo za okolje in prostor, World bank, Ljubljana.

Geografski informacijski sistemi v Sloveniji, zborniki bienalnih simpozijev od 1991-1992 do 2001-2002. Zveza geografskih društev Slovenije, Zveza geodetov Slovenije, različni (so)izdajatelji, Ljubljana.

Krevs, M. 1999. Geoinformatika v Sloveniji. Gradivo za udeležence in predavatelje. Izobraževalno središče za geomatiko, temeljni nivo. Projekt ONIX: Inštitut za geodezijo in fotogrametrijo, Ministrstvo za okolje in prostor, World bank, Ljubljana.

Krevs, M. 2000. Uporaba GIS-a pri oblikovanju volilnih okrajev v Sloveniji. V: Hladnik, D., Krevs, M., Perko, D., Podobnikar, T., Stančič, Z. (uredniki), Geografski informacijski sistemi v Sloveniji 1999-2000. Zbornik simpozija v Ljubljani, 26.9.2000. ZRC SAZU, Zveza geografskih društev Slovenije, Zveza geodetov Slovenije, Ljubljana, 227-232.

Krevs, M. 2001. Geoinformatika na slovenskih geografskih ustanovah. Rezultati intervjujev. Oddelek za geografijo, Filozofska fakulteta, Ljubljana.

Peršolja, T. 2001. Ankete o usmeritvi (ped./neped.) študija geografije. Geomix, številka 1, december 2001. Društvo mladih geografov Slovenije, Ljubljana, 13.

Triglav, J. 1996. Geomatika, mozaik merskih metod. Življenje in tehnika, poseb. izdaja. Tehniška založba Slovenije, Ljubljana.

\section{GEOINFORMATICS AND APPLIED GEOGRAPHY IN SLOVENIA}

\section{Summary}

In the last decade we contentedly find out the growing use of geoinformatics documented in Slovenian geographical literature, from undergraduate students' reports, dissertations, to research project reports. But the possibilities of effici- 
ent use of geoinformatics in geographical pedagogical, scientific and applied work are far from being exhausted.

Although the text is on applied geography, we do not try to divide it from other (non-applied?) part of geography. For example, the use of geoinformatics at the university (or even lower level of education) is very much related to it's use in applied geography, and vice versa.

Actual use of geoinformatics in Slovenian (applied) geography is confronted with the mentioned possibilities of efficient use of geoinformatics. The first is evaluated on the basis of a review of Slovenian geographical literature (published and some unpublished) and interviews with professionals from the five "geographical institutions « in Slovenia, responsible for geoinformatics in their institutions and activelly participating in the development of the geoinformatics in Slovenia. Possibilities of efficient use of geoinformatics are derived from the »insider « knowledge of geoinformatics and experiences published in international geographical literature.

Description of the current use of geoinformatics in slovenian geography:

- basic division between the institutions: research institutions (three institutes), and pedagogical and research institutions (two departments of geography);

- prevailing fields of use of geoinformatics: »descriptive « geoinformatic tools (e.g. descriptive statistics, classifications, »classical« thematic cartography), data management, evaluations of landscape or policies;

- poorly used geoinformatical opportunities: e.g. dinamical modelling (simulations, scenarios), development of new geoinformatic methods (and not only adjustment of research project designs to the existing methods and technology), internet geoinformatical products, 3D and dynamical geographical visualization; their use would have positive effects on the quality of the research itself, and in applied geography especially on the adaptation to the market needs (persuasiveness, attractiveness, intelligibility, accessibility of the results, products) and to the needs of the consumer of the geoinformation, stimulation of the interdisciplinarity, archiving and comparing practices.

Among the main reasons for these conditions are weak cooperation among geographical institutions, among »scientific«, »pedagogic« and »applied « geography, missed opportunities of relating geographical themes to geoinformatics in the implementation of the undergraduate study programme, limited opportunities of geoinformatical education and trainning, lack of adequately educated and trainned »geoinformaticians«, and quick changes in research project themes, usually demanding quick results. 
Possible actions to improve fruitful interweaving of geoinformatics and Slovenian (applied) geography could be the following:

- step forward in undergraduate and postgraduate study programme (adding geoinformatic orientation of the study to the existing »geographical« ones),

- complementing a part of the work of at different institutions, especially work relating to the the common themes (and not under too severe time preasure), following a permanent joint search of market niches or creation of new geoinformatic needs;

- probably a joint geoinformatic service for the geographical and other institutions should be considered. 